\title{
Visual cues as determinants of perceptual range in root voles Microtus oeconomus
}

\author{
Harry P. ANDREASSEN, Erik BJøRNBOM, Rine G. CARLSEN, \\ Gry GUNDERSEN and Hege GUNDERSEN
}

\begin{abstract}
Andreassen H. P., Bjørnbom E., Carlsen R. G., Gundersen G. and Gundersen H. 1998. Visual cues as determinants of perceptual range in root voles Microtus oeconomus. Acta Theriologica 43: 371-378.

We tested whether the perceptual range of male root voles Microtus oeconomus (Pallas, 1776) could be determined by visual objects in the landscape. This was done by giving single males the choice between three different sized visual cardboard patches randomly arranged around the perimeter of a circle located in agricultural fields. Effects of distance were tested by varying the diameter of the circle. The root voles were able to orient towards patches, but did not choose patches relative to their size. The ability to orient towards patches decreased with increasing distance between the release point and the patches.

Department of Biology, Division of Zoology, University of Oslo, P.O. Box 1050 Blindern, N-0316 Oslo, Norway, e-mail: harry.andreassen@bio.uio.no
\end{abstract}

Key words: landscape ecology, Microtus oeconomus, perceptual range, searching behaviour

\section{Introduction}

The distance from which a landscape element can be perceived as such was defined by Lima and Zollner (1996) as the perceptual range for a given animal, and has been applied in several population models at the landscape level (eg Doak et al. 1992, Liu et al. 1995). Empirically, however, our knowledge of perceptual range and the cues used for orientation is limited to the insect literature (Bell 1991, Ray et al. 1991, see also Lima and Zollner 1996). Furthermore, the perceptual mechanisms concerning searching, exploration, and escape behaviour in mammals has most often been studied in a psychological or neurological context (see eg Alyan and Jander 1994 and references therein), and seldomly related to conservation biology or landscape ecology (see Lima and Zollner 1996).

We performed an experiment to test the extent to which male root voles Microtus oeconomus (Pallas, 1776) use visual cues during movements in agricultural fields. Specifically we examined how patch size and distance to patches on a microhabitat scale affect the direction of movement. We used cardboard sheets as 
visual cues, assuming that the root voles would perceive them as patches with a relatively high probability of encountering protection. Previous studies of root voles have shown that gaps between 2 and $4 \mathrm{~m}$ hinder movements in unfamiliar dispersal corridors (Andreassen et al. 1996a), and that interpatch distances between 4 and $9 \mathrm{~m}$ limit the use of multiple fragments within a familiar home range (Berg 1995, J. Fauske, unpubl.). The perceptual range of root voles seems therefore to be somewhere between 2 and $9 \mathrm{~m}$. Here we attempted to reveal whether visual objects could be used as perceptual cues and thereby explain the mechanisms determining root vole perceptual range. We predicted that if visual cues are important in root vole movement: (1) the root voles would choose a direction towards a sheet of cardboard more often than expected from a random direction of movement, (2) the root voles would miss the cardboard sheets more often when the distance from the release point increased due to short-sightedness (eg shown for wood lemmings Myopus schisticolor by Rahman and Rahman 1966), and (3) the root voles would choose large cardboard sheets rather than small cardboard sheets due to higher probability of encountering protection.

\section{Material and methods}

The experiment was performed on experimental fields at Evenstad Research Station, Hedmark County, SE Norway, June 6-12, 1993. The study area consisted of two experimental circles, each with a radius of $10 \mathrm{~m}$, in a newly mowed lawn. Outside the experimental circles there were agricultural areas with about $10 \mathrm{~cm}$ high grass vegetation.

In the middle of the experimental circle we placed a release point consisting of a cake dish $(30 \mathrm{~cm}$ diameter) with a lid of plexi glass. The lid was attached to a string so we could carefully lift the lid upwards by pulling the string when sitting outside the experimental circle. To simulate patches we used green sheets of cardboard in three different sizes: $0.1 \mathrm{~m}, 0.25 \mathrm{~m}$ and $0.7 \mathrm{~m}$ wide; all $0.5 \mathrm{~m}$ tall. We expected that the animals would perceive the cardboard sheets as objects with possible shelter. The simulation of cardboard patches had the beneficial property that they were easily moved, so that their position could be altered between individual experimental trials to control for possible biases from factors such as the position of the sun and scent from previous trials. The experimental circle was divided into 6 sectors, and each of the 3 sheets of cardboard were situated in standing position within one of the sectors so that there was an empty sector in between each of the cardboard patches. Three different distances between the release point and the patches (release - patch distance) were used $(0.5 \mathrm{~m}, 2 \mathrm{~m}$ and $5 \mathrm{~m})$.

Eighteen different adult male root voles, reared at the Animal Division, University of Oslo, participated in the experiment. Males were chosen as they show more willingness to move in this type of short term experiments than females (H. P. Andreassen, pers. obs.). The animals were released singly by placing them within the cake dish for 1 minute before the onset of each trial (lifting of the lid). Each trial was terminated when the animal had reached a patch (see Fig. 1), or crossed the perimeter of the experimental circle with a radius equal to the distance between the release point and the patches. Four trials were also terminated because the individual did not move for 10 minutes. To diminish the possible directional choice due to previous trials, the cake dish was washed between each trial. The position of patches (both the distance from release point and the specific sector for each patch for a given distance), as well as the sequence of individuals used, were randomised before each trial. The restriction to the randomisation was only that each individual should be tested only once in each of the 3 distances to the patches, and also that all individuals were used in a trial before the 
reuse of individuals. There were always $2-4$ observers located outside the experimental circle ( $>10$ $\mathrm{m}$ away from the release point). The observers stood or sat quietly during observations, and at no fixed positions. The positions of the observer should therefore not bias the results.

We registered patch size chosen (if any), the direction of movement within one of the 6 sectors, searching time (the time lapse from start till termination of a trial) and speed (searching time divided by the distance between the release point and the patches). Due to cells with low expected frequencies in certain analyses, we chose to use statistics with Gamma distributed error terms adjusted for small samples $\left(G_{\text {adj }}\right)$, according to Williams (1976), in all crosstabulations and goodness of fit tests.

The relevance of our results may be questioned if individuals moved according to previous experience, or the previous trial. There was, however, no association between the number of trials an individual had been used in and movements towards a patch versus missing the patches, choice of patch size or direction of movement (all $p<0.20$ ). In addition, the direction of movement was not associated by the previous trial $\left(G_{\text {adj }}=0.06, \mathrm{df}=1, p>0.75\right)$. We therefore assume each trial to be a statistically independent event.

\section{Results}

If the animal walked in a random direction, unaffected by the patches, we expected the probability of reaching a patch to be proportionate to the width of the patch. Thus, for each patch size and release - patch distance, we estimated the expected frequency with which an animal would encounter the patch as the proportion of the perimeter of the experimental circle covered by the patch (Table 1). For all release - patch distances animals moved towards a patch more often than would be expected from a random choice of direction (Table 1). However, there was an association between the number of times individuals reached a patch and distance to the patch $\left(G_{\text {adj }}=6.90, \mathrm{df}=2, p<0.05\right)$. Loglinear modelling showed that there was a significantly lower odds ratio for reaching a patch for the longest release - patch distance $(5 \mathrm{~m})$ tested $(0.14 ; 95 \%$ conf. int.: $0.03-0.67)$,

Table 1. Observed and expected frequencies of reaching different sized patches (or no patch reached) for the three different distances tested between the release point and the patches (release - patch distance), and the number of trials terminated because the animal did not move. Goodness of fit tests take only the counts of reaching and not reaching a patch into account (patch sizes lumped), all $p<0.001$.

\begin{tabular}{|c|c|c|c|c|c|c|c|}
\hline \multirow{2}{*}{$\begin{array}{l}\text { Release - } \\
\text { patch } \\
\text { distance }\end{array}$} & \multirow{2}{*}{ Category } & \multicolumn{4}{|c|}{ Patch size } & \multirow{2}{*}{$\begin{array}{c}\text { Trial } \\
\text { terminated }\end{array}$} & \multirow{2}{*}{$\begin{array}{l}\text { Goodness of fit } \\
\qquad \begin{array}{c}(1 \mathrm{df}) \\
G_{\mathrm{adj}}\end{array}\end{array}$} \\
\hline & & No patch & $0.1 \mathrm{~m}$ & $0.25 \mathrm{~m}$ & $0.7 \mathrm{~m}$ & & \\
\hline $0.5 \mathrm{~m}$ & $\begin{array}{l}\text { Observed } \\
\text { Expected }\end{array}$ & $\begin{array}{c}4 \\
12.0\end{array}$ & $\begin{array}{l}4 \\
0.6\end{array}$ & $\begin{array}{l}4 \\
1.4\end{array}$ & $\begin{array}{l}6 \\
4\end{array}$ & 0 & 14.53 \\
\hline $2.0 \mathrm{~m}$ & $\begin{array}{l}\text { Observed } \\
\text { Expected }\end{array}$ & $\begin{array}{c}6 \\
15.6\end{array}$ & $\begin{array}{l}1 \\
0.1\end{array}$ & $\begin{array}{l}5 \\
0.4\end{array}$ & $\begin{array}{l}5 \\
0.9\end{array}$ & 1 & 32.63 \\
\hline $0.5 \mathrm{~m}$ & $\begin{array}{l}\text { Observed } \\
\text { Expected }\end{array}$ & $\begin{array}{l}10 \\
14.5\end{array}$ & $\begin{array}{l}0 \\
0.1\end{array}$ & $\begin{array}{l}1 \\
0.1\end{array}$ & $\begin{array}{l}4 \\
0.3\end{array}$ & 3 & 15.09 \\
\hline
\end{tabular}


Table 2. Number of movements into the 6 different sectors in the two experimental circles, with goodness of fit test.

\begin{tabular}{llcc}
\hline Sector & Circle 1 & Circle 2 & $\begin{array}{c}\text { Circle 1 } \\
\text { and 2 }\end{array}$ \\
\hline 1 & 9 & 5 & 14 \\
2 & 3 & 4 & 7 \\
3 & 2 & 1 & 3 \\
4 & 4 & 1 & 5 \\
5 & 6 & 7 & 13 \\
6 & 3 & 5 & 8 \\
$G_{\text {adj }}$ & 6.67 & 8.40 & 11.56 \\
df & 5 & 5 & 5 \\
$p$ & 0.25 & 0.07 & 0.05 \\
\hline
\end{tabular}

compared to the shortest distance tested $(0.5 \mathrm{~m}$; odds ratio alliased $=1)$. The odds ratio for reaching a patch for the $2 \mathrm{~m}$ release - patch distance did not differ significantly from the two other distances (odds ratio $=0.52 ; 95 \%$ conf. int. $0.12-2,33)$.

To test whether there was any preference for patch size, we lumped all trials irrespective of release-patch distance. Most of the individuals that reached a patch, chose the largest patch (Table 1). This could be accounted for by the larger probability of reaching this patch (goodness of fit test for data lumped over the distance classes: $G_{\text {adj }}=3.61$, $\mathrm{df}=2$, $p>0.10$ ).

Animals did not move randomly into sectors of the circle. Rather, the animals tended to use two sectors of the experimental circle more often than the other 4 (Table 2). The same two sectors were most frequently used in both experimental circles, but the difference in use was not statistically significant for separate analysis of each experimental circle (Table 2). This was not due to an accidental skewed randomisation of patch location (experimental circles analysed separately: both $G_{\text {adj }}<0.72, \mathrm{df}=1, p>0.50$; or together: $\left.G_{\text {adj }}=0.02, \mathrm{df}=1, p>0.90\right)$. Both of the sectors most often chosen pointed towards separate mountain tops (Fig. 1).

We were not able to detect any difference in time spent searching (Kruskal-Wallis, $H=0.98, p=0.32$ ), or speed of movements (Kruskal-Wallis, $H<0.26$,

Table 3. Time spent searching (release till termination of a trial), and speed of movement (time spent searching / release - patch distance), presented as minutes (mean $\pm \mathrm{SE}$ ), for different patch sizes (and no patch reached) and release - patch distance. Sample size shown in Table 1.

\begin{tabular}{|c|c|c|c|c|}
\hline \multirow{2}{*}{$\begin{array}{l}\text { Release - patch } \\
\text { distance }\end{array}$} & \multicolumn{4}{|c|}{ Patch size } \\
\hline & No patch & $0.1 \mathrm{~m}$ & $0.25 \mathrm{~m}$ & $0.7 \mathrm{~m}$ \\
\hline \multicolumn{5}{|c|}{ Time spent searching } \\
\hline $0.5 \mathrm{~m}$ & $0.61 \pm 0.24$ & $1.30 \pm 0.54$ & $0.16 \pm 0.05$ & $0.14 \pm 0.06$ \\
\hline $2.0 \mathrm{~m}$ & $1.03 \pm 0.26$ & $2.12 \pm 0$ & $1.33 \pm 0.88$ & $1.11 \pm 0.37$ \\
\hline $5.0 \mathrm{~m}$ & $1.11 \pm 0.37$ & - & $5.00 \pm 0$ & $1.51 \pm 1.17$ \\
\hline \multicolumn{5}{|c|}{ Speed of movement } \\
\hline $0.5 \mathrm{~m}$ & $1.15 \pm 0.31$ & $2.06 \pm 1.69$ & $6.13 \pm 3.53$ & $7.13 \pm 2.23$ \\
\hline $2.0 \mathrm{~m}$ & $2.90 \pm 0.80$ & $0.94 \pm 0$ & $3.85 \pm 1.00$ & $3.76 \pm 1.72$ \\
\hline $5.0 \mathrm{~m}$ & $19.30 \pm 7.52$ & - & $1.00 \pm 0$ & $14.83 \pm 6.95$ \\
\hline
\end{tabular}




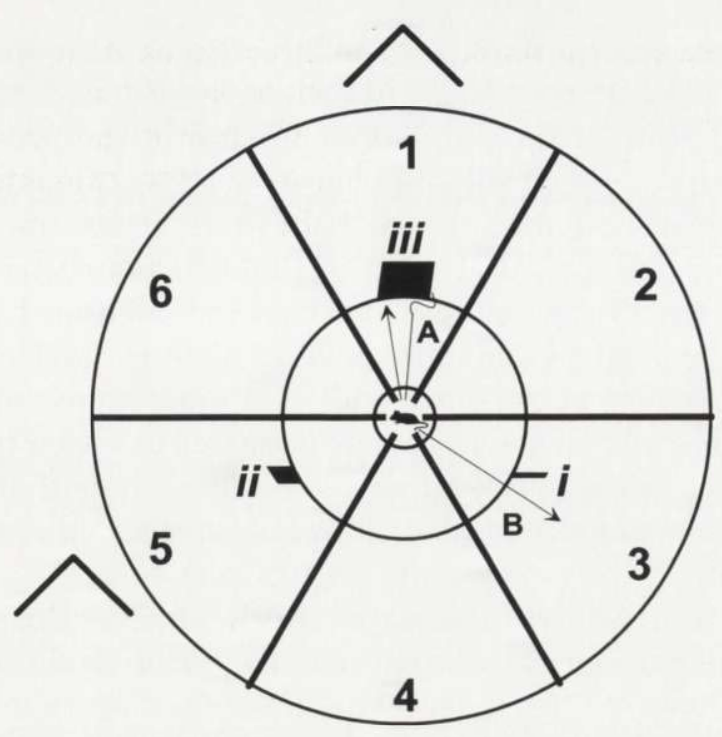

Fig. 1. The experimental set-up, presenting the 3 experimental distances used (circles), the 6 sectors and the 3 patches (i-iii). The lines marked with an A illustrate movements of animals that reached a cardboard sheet whereas line B illustrate the movement of an individual that did not reach a cardboard sheet.

$p>0.61$, between animals that reached a patch compared to those that did not reach a patch (Table 3 ). Time spent searching increased with increasing distance between the release point and the patches (Kruskal-Wallis, $H=8.65, p=0.01$ ). This was not due to different distances of movement only, because animals also increased speed of their movements with longer distances between the release point and the patches (Kruskal-Wallis, $H=6.62, p=0.04$ ). For those animals that reached a patch, time spent searching did not differ between animals that chose different sized patches (Kruskal-Wallis, $H<1.97, p=0.37$ ), but speed increased with increasing size of chosen patch (Kruskal-Wallis, $H=6.23, p=0.04$ ) (Table 3 ).

\section{Discussion}

Our results showed that male root voles are able to orient towards visual objects. As the relative success for reaching a sheet of cardboard seemed to decrease with increasing distance from the release point, we suggest that male root voles can visually identify objects in unfamiliar environments only at short distances. Male root voles did not select cardboard patches according to size as we had expected, although individuals that selected the larger cardboard patches 
seemed to be more decisive in their choice of direction as their speed of movements was higher.

The motivational state of the animals is obscure in the present study, as we have made no attempt to reveal whether the voles chose the patches of cardboard on the basis of exploration and search behaviour or as the result of escape behaviour. We think, however, that most of the behaviour was risk aversive, as animals often chose the first possible cover observed. Neither have we attempted to separate between visual parameters such as distance and retinal image size (Day 1972), because the response of the vole in a landscape context would be the same whether the detection of visual objects were due to visual perceived distance or retinal image size. Our experiment does, however, show that visual cues may be used during movements of root voles in a landscape, and reveals one possible mechanism determining the perceptual range of root voles.

Few mammal studies have attempted to determine the degree to which mammals use visible cues for orientation under natural conditions (but see Mech 1970). There have, however, been several studies relating to mammal searching behaviour performed under laboratory conditions, without the complicating factors associated with experiments under natural conditions. We have presented an experiment performed under seminatural conditions, which might be a step closer to reality. In fact, the cardboard patches used in the present study do in size resemble the highly patchy, discrete, small willow thickets which provide cover for root voles under natural conditions (H. P. Andreassen, pers. obs.). Our results, showing that visible cues may occasionally be used for orientation in unfamiliar areas, coincide with laboratory experiments on homing behaviour (eg Alyan and Jander 1994). Although the results of both laboratory experiments and the present study may have questionable relevance to natural conditions, they illuminate potential abilities of particular groups of animals. This provides elements for an understanding of the mechanisms underlying searching behaviour in general.

That the animals did not move into independent sectors of the experimental circle may have been a result of our seminatural design. We can only make a posteriori speculations on uncontrolled external factors that could cause this anomaly in our result. As the two sectors most often used in both experimental circles were oriented towards two large landscape features, we suggest that future studies should search for the possibility that animals relate visually to several scales by moving short distances according to shelter in the microhabitat configuration, but with a main direction according to the macrohabitat (see also Kopponen et al. 1961, Henttonen and Kaikusalo 1993). Similar results, indicating the significance of distant cues, have been shown for smaller spatial scales under laboratory conditions (Honig 1990, Alyan and Jander 1994, Herz et al. 1994).

Our results have some implication for the understanding of the mechanisms underlying movement ecology (Ims 1995). Root voles (Steen 1994), as well as other microtines (Szacki and Liro 1991), are known to perform some long distance movements (several kilometres), where animals will be searching in novel areas. 
Previous studies of microtines under natural conditions, or outside enclosures, have shown that space use within a home range may be affected by conspecifics (Myllymäki 1977, Gaines and Johnson 1982) as well as predators (Jędrzejewski et al. 1993), but such responses was not detectable in experiments on dispersing root voles searching in unfamiliar areas (Andreassen et al. 1996a). Hence, there may be a difference in which orientation cues are used in familiar (within a home range) and in unfamiliar environments. In unfamiliar areas we show that visible cues may alter movement direction, while existing data suggest that olfactory cues might be less important during dispersal (Andreassen et al. 1996a).

Our results also have some connotation for the understanding of connectivity in landscape ecology (Wiens et al. 1993). Connectivity is regarded as habitat structures, for instance habitat corridors, or degree of isolation between habitat fragments (Forman and Godron 1986, Rolstad and Wegge 1987). Andreassen et al. (1996b) showed that $4 \mathrm{~m}$ long gaps in a dispersal corridor inhibited movements of dispersing male root voles. The mechanism behind this may be that the continuity of the corridor is not detected by the animal, because of distance constrained vision. Consequently, for management purposes, there should be a demand for empirical data on detection distances for a variety of species (see also Lima and Zollner 1996).

Acknowledgements: R. A. Ims, J. Aars, H. Henttonen, H. Steen and R. Jander commented on the manuscript. We are also grateful to members of the Animal Division for taking care of the animals. This study is a contribution to the project "Habitat fragmentation: implications for the dynamics of populations", and was supported financially by the Norwegian Research Council (NFR) and the Nansen Endowment Foundation.

\section{References}

Alyan S. and Jander R. 1994. Short-range homing in the house mouse, Mus musculus: stages in the learning of directions. Animal Behaviour 48: 285-298.

Andreassen H. P., Halle S. and Ims R. A. 1996a. Optimal width of movement corridors for root voles: not too narrow and not too wide. Journal of Applied Ecology 33: 63-70.

Andreassen H. P., Ims R. A. and Steinset O. K. 1996b. The effects of discontinuity of movement corridors on male root vole movements. Journal of Applied Ecology 33: 555-560.

Bell W. J. 1991. Searching behaviour. Chapman and Hall, London: 1-351.

Berg K. W. 1995. Space use responses of root voles (Microtus oeconomus) to a habitat fragmentation gradient. Candidatus Scientiarum thesis, University of Oslo, Oslo: 1-51.

Day R. H. 1972. Visual spatial illusions: a general explanation. Science 175: 1335-1340.

Doak D. F., Marino P. C. and Kareiva P. M. 1992. Spatial scale mediates the influence of habitat fragmentation on dispersal success: implications for conservation. Theoretical Population Biology 41: $315-336$.

Forman R. T. T. and Godron M. 1986. Landscape ecology. John Wiley and Sons, New York: 1-619.

Gaines M. S. and Johnson M. L. 1982. Home range size and population dynamics in the prairie vole, Microtus ochrogaster. Oikos 39: 63-70.

Henttonen H. and Kaikusalo A. 1993. Lemming movements. [In: The biology of lemmings. N. C. Stenseth and R. A. Ims, eds]. Academic Press, London: 157-186. 
Herz R. S., Zanette L. and Sherry D. F. 1994. Spatial cues for cache retrieval by black-capped chickadees. Animal Behaviour 48: 343-351.

Honig W. K. 1990. Structure and function in the spatial memory of animals. [In: Memory mechanisms: A tribute to G. V. Goddard. W. C. Abraham, M. Corballis and K. G. White, eds]. Hillsdal, New Jersey: 293-313.

Ims R. A. 1995. Movement patterns related to spatial structures. [In: Mosaic landscapes and ecological processes. L. Hansson, L. Fahrig and G. Merriam, eds]. Chapman and Hall, London: 85-109.

Jędrzejewski W., Rychlik L. and Jędrzejewska B. 1993. Responses of bank voles to odours of seven species of predators: experimental data and their relevance to natural predator-vole relationships. Oikos 68: 251-257.

Koponen T., Kokkonen A. and Kalela O. 1961. On a case of a spring migration in the Norwegian lemming. Annales Academiae Scientiarum Fennicae, Series A, IV Biologica 52: 1-30.

Lima S. L. and Zollner P. A. 1996. Towards a behavioral ecology of ecological landscapes. Trends in Ecology and Evolution 11: 131-135.

Liu J., Dunning J. B. Jr and Pulliam H. R. 1995. Population effects of a forest management plan on Bachman's sparrows (Aimophila aestivalis): linking a spatially explicit model with GIS. Conservation Biology 9: 62-75.

Mech L. D. 1970. The wolf: The ecology and behavior of an endangered species. Natural History Press, New York: $1-384$.

Myllymäki A. 1977. Intraspecific competition and home range dynamics in the field vole Microtus agrestis. Oikos 29: 553-564.

Rahmann von H. and Rahmann M. 1966. Sehschärfe (Minimum separabile), Dressurverhalten und vegleichende Augenlinsenmessungen beim Waldlemming (Myopus schisticolor Lillj.) und Berglemming (Lemmus lemmus L.). Zeitschrift für Säugertierkunde 31: 396-401.

Ray C., Gilpin M. and Smith A. T. 1991. The effect of conspecific attraction on metapopulation dynamics. Biological Journal of Linnean Society 42: 123-134.

Rolstad J. and Wegge P. 1987. Distribution and size of capercaillie leks in relation to old forest fragmentation. Oecologia 72: 389-394.

Steen H. 1994. Low survival of long distance dispersers of the root vole (Microtus oeconomus). Annales Zoologici Fennici 31: 271-274.

Szacki J. and Liro A. 1991. Movements of small mammals in the heterogeneous landscape. Landscape Ecology 5: 219-224.

Wiens J., Stenseth N. C., Van Horne B. and Ims R. A. 1993. Ecological mechanisms and landscape ecology. Oikos 66: 369-380.

Williams D. A. 1976. Improved likelihood ratio tests for complete contingency tables. Biometrika 63: 33-37.

Received 24 July 1997, accepted 24 June 1998 